\title{
Effect of inhaled heparin on lung function and coagulation in healthy volunteers
}

\author{
K.E. Bendstrup*, J. Gram*, J.I. Jensen*
}

Effect of inhaled heparin on lung function and coagulation in healthy volunteers. K.E. Bendstrup, J. Gram, J.I. Jensen. (C)ERS Journals Ltd 2002.

ABSTRACT: The aim of the present study was to investigate the safety of increasing doses of a well-defined lower respiratory tract (LRT) dose of inhaled heparin with regard to pulmonary function and coagulation.

Ten volunteers inhaled heparin from Sidestream jet nebulizers loaded with $\mathbf{1 0 0 , 0 0 0}$, $200,000,300,000$ or 400,000 International Units (IU) of heparin. Lung function, antifactor (anti)-Xa, activated partial thromboplastin time (APTT), tissue factor pathway inhibitor (TFPI), whole blood clotting time, platelets, von Willebrand factor, and $\mathrm{C}$-reactive protein were determined before and $1,3,6$, and $24 \mathrm{~h}$ after inhalation.

The highest LRT dose was 32,000 IU heparin. Inhaled heparin did not affect pulmonary function. The area under the curve of the anti-Xa activity increased with increasing doses of heparin $(\mathrm{p}=\mathbf{0 . 0 0 5})$, but remained unchanged for all other variables. Peak anti-Xa activity was $0.113 \mathrm{IU} \cdot \mathrm{mL}^{-1} 6 \mathrm{~h}$ after inhalation of 400,000 IU heparin. When compared to baseline values: anti-Xa increased after $200,000(p=0.03), 300,000$ $(\mathrm{p}=\mathbf{0 . 0 0 4})$, and 400,000 IU ( $\mathrm{p}=\mathbf{0 . 0 0 2})$ heparin; APTT increased to a maximum of 1.03 $6 \mathrm{~h}$ after inhalation of 400,000 IU heparin $(\mathrm{p}=0.05)$; TFPI increased after 100,000 $(p=0.01), 200,000(p=0.01), 300,000(p=0.006)$ and 400,000 IU $(p<0.001)$.

Inhaled heparin delivery of 32,000 International Units to the lower respiratory tract can safely be inhaled for clinical or research purposes.

Eur Respir J 2002; 19: 606-610.
*Dept of Internal Medicine and ${ }^{\#}$ Dept of Clinical Biochemistry and Thrombosis Research, Esbjerg Hospital, University of Southern Denmark, Esbjerg, Denmark.

Correspondence: K.E. Bendstrup

Stampesvej 57

7100 Vejle

DK-7100 Denmark

E-mail: bendstrup@dadlnet.dk

Keywords: Aerosol

coagulation

heparin

lung function

Received: December 192000

Accepted after revision October 12001

This study was supported by grants from the Danish Lung Association.
The effects of inhaled heparin on bronchial asthma have been the subject of several studies [1-7] because heparin possesses anti-inflammatory properties. Results from these studies have been inconsistent, possibly because of the administration of different and unquantified doses of heparin to the lower respiratory tract (LRT). Different aerosol-generating devices have been used. Ultrasonic nebulizers produce aerosols with a greater particle size than jet nebulizers [8] and the LRT dose from an ultrasonic nebulizer may thus be quite small. In addition, the output from jet nebulizers is often overestimated due to evaporative water loss during nebulization [9], leading to smaller amounts of drug deposited in the LRT than expected. Furthermore, different groups of patients have been studied and the effects of heparin have been assessed using different methods of provocation, such as exercise, allergens, histamine, methacholine, adenosine, adenosine monophosphate (AMP) and metabisulphite [1-7], making comparisons difficult.

None of the previous studies have investigated the properties of heparin aerosols generated by different nebulizers or accurately measured the dose of inhaled heparin deposited in the LRT. The authors have previously characterized heparin aerosols generated by a jet and an ultrasonic nebulizer with respect to particle size and output [10]. It was found that high heparin concentrations and driving flow rates of the Sidestream jet nebulizer (Medic-Aid, Bognor Regis, UK) generated heparin aerosols with smaller particle sizes compared to that of the Ultraneb 2000 ultrasonic nebulizer (DeVilbiss, Langen, Germany). Thus, the estimated LRT dose was highest with the jet nebulizer. Subsequently, it was determined by scintigraphy that 7,000 International Units (IU) were deposited in the LRT after a single nebulization of 90,000 IU of ${ }^{99 \mathrm{~m}}$ Tc-heparin [11].

In order to investigate the possible use of inhaled heparin in pulmonary disease, the LRT doses must be well defined and quantified, and their effect on the systemic coagulation and on pulmonary function must be known. Therefore, safe doses of inhaled heparin must be established.

Consequently, the aim of the present study was to investigate the effect of increasing doses of inhaled heparin on pulmonary function and the coagulation system. The effect on the coagulation system is described by the following. 1) The effect on circulating blood: activated partial thromboplastin time (APTT), antifactor (anti)-Xa and whole blood clotting time (WBCT). 2) The effect on endothelial cells: release of tissue factor pathway inhibitor (TFPI) and von Willebrand factor (vWF). 3) The adverse effect: platelets. In addition, a possible systemic inflammatory effect is described by $\mathrm{C}$-reactive protein (CRP). 


\section{Materials and methods}

\section{Nebulizers and heparin}

Unfractionated sodium heparin in a concentration of $25,000 \mathrm{IU} \cdot \mathrm{mL}^{-1}$ (Leo Pharmaceutical Ltd, Copenhagen, Denmark) and four Sidestream jet nebulizers (Medic-Aid) from the same lot were used.

\section{Study population}

Ten healthy volunteers (three males) were included in the study (mean age $43 \mathrm{yrs}$; mean weight $74 \mathrm{~kg}$ ). All had normal lung function (mean \pm SD: forced expiratory volume in one second (FEV1) $104 \pm 11 \%$ predicted; forced vital capacity (FVC) $112 \pm 11 \%$ pred; and $\mathrm{FEV} 1 / \mathrm{FVC} 96 \pm 7 \%$ pred) and coagulation variables within the reference intervals (APTT 1.01 \pm 0.10 (pred 0.90-1.20); prothrombin time $0.99 \pm 0.06$ (pred $0.8-1.20$ ); platelets $290 \pm 49$ (pred $160-340 \times 10^{9} \cdot \mathrm{L}^{-1}$ ). All volunteers also had normal chest radiographs and histamine challenge tests (provocative dose causing a $20 \%$ fall in FEV1 (PD20) $>8 \mathrm{mg} \cdot \mathrm{mL}^{-1}$ histamine).

Exclusion criteria were pulmonary diseases, haemorrhagic disorders, pregnancy or breastfeeding, gastric ulcer or gastrointestinal bleeding, heparin allergy, and anticoagulation therapy. Two of the volunteers were treated for arterial hypertension with metoprolol and lisinopril, respectively, one was treated with hormone replacement therapy, and one with a multivitamin preparation.

Each subject provided written informed consent. The study was approved by the local Ethics Committee.

\section{Administration of aerosol}

The subjects inhaled heparin on four different days with an interval of $\geqslant 14$ days to ensure washout of heparin. Doses of 100,000, 200,000, 300,000, and 400,000 IU were loaded into one, two, three or four nebulizers. This corresponded to $\sim 8,000,16,000$, 24,000 , and $32,000 \mathrm{IU}$ of heparin administered to the LRT [11].

Sodium heparin ( $4 \mathrm{~mL}$, concentration $25,000 \mathrm{IU} \cdot \mathrm{mL}^{-1}$ ) was loaded into the Sidestream jet nebulizers driven at a flow rate of $10 \mathrm{~L} \cdot \mathrm{min}^{-1}$. Subjects wore a noseclip and inhaled heparin by normal tidal breathing for 15 min through a mouthpiece until visible aerosol generation stopped. Thus, for each dose, inhalation time was 15, 30, 45 and $60 \mathrm{~min}$, respectively.

Pulmonary function tests and blood samples were obtained before inhalation and 1, 3, 6 and $24 \mathrm{~h}$ after the beginning of the last nebulization.

\section{Lung function}

The following pulmonary function variables were measured by body plethysmography: FEV1, FVC, Tiffenau's index (FEV1/FVC), peak expiratory flow (PEF), and specific airway conductivity (sGaw) (SensorMedics, Bilthoven, the Netherlands).

\section{Blood sampling}

All blood samples were drawn by an experienced laboratory technician through venipuncture in the antecubital vein, after the subject had rested for $15 \mathrm{~min}$ in a chair. A minimum of stasis was applied. The samples were processed immediately after collection, as described later. Plasma for vWF, anti-Xa, TFPI, and CRP was stored at $80^{\circ} \mathrm{C}$ for later analysis, while WBCT, APTT, and platelets were analysed immediately.

\section{Coagulation assays}

Blood for APTT determination was collected in citrated tubes $\left(0.5 \mathrm{~mL}, 0.129 \mathrm{~mol} \cdot \mathrm{L}^{-1}\right.$ sodium citrate). The surface-induced plasma coagulation was determined by mixing equal volumes of plasma and Cephotest reagent (Nycomed, Oslo, Norway). The mixture was incubated for $6 \mathrm{~min}$ at $37^{\circ} \mathrm{C}$ and recalcified. The time to coagulation was recorded using automated equipment (Behring Coagulation System, Dade Behring, Marburg, Germany). The result was expressed as the ratio between the coagulation time in the sample and the geometric mean of the coagulation time from 20 healthy volunteers.

Blood for anti-Xa activity determination was collected in CTAD tubes $(0.5 \mathrm{~mL}$ sodium citrate and citric acid $0.109 \mathrm{M}$ with inhibitors of platelet aggregation (theophylline, adenosine, dipyramidole)). Blood was centrifuged at $2,000 \times g$ for $20 \mathrm{~min}$ at $20^{\circ} \mathrm{C}$ before being stored at $-80^{\circ} \mathrm{C}$. Anti-Xa activity in plasma was measured with the chromogenic substrate S-2732S (Coatest heparin/heparin on Cobas Mira, Chromogenix, Instrumentation Laboratory, $\mathrm{CH}$ Werfen, Barcelona, Spain).

WBCT was determined with a Hemochron $\AA$ coagulometer (International Technidyne Corporation, NJ, USA). Blood (5 mL) was collected in Hemochron $\mathbb{R}$ tubes (H106). Coagulation was activated by the glass surface. WBCT was measured in duplicate and the mean of these was used.

Blood for TFPI determination was collected in citrated tubes and centrifuged twice at $2,000 \times g$ for $20 \mathrm{~min}$ at $20^{\circ} \mathrm{C}$. Plasma concentrations of TFPI $\left(\mathrm{ng} \cdot \mathrm{mL}^{-1}\right)$ were measured by enzyme linked immunosorbent assay (ELISA) (Imubind ${ }^{\mathrm{TM}}$, American Diagnostica Inc., Greenwich, CT, USA) using a rabbit antihuman TFPI polyclonal antibody as a capture antibody and a monoclonal detection antibody directed against part of the TFPI molecule. In this way, lipoprotein-bound and free TFPI were determined.

Blood for $\mathrm{vWF}$ determination was collected in citrated tubes and centrifuged at $2,000 \times g$ for $20 \mathrm{~min}$ at $4{ }^{\circ} \mathrm{C}$. The protein concentration of vWF was determined with an ELISA method (DAKO, Copenhagen, Denmark).

Blood for platelet counts was collected in ethylenediamine tetraacetic acid (EDTA) tubes $(5.9 \mathrm{mg}$ EDTA $\left.3 \mathrm{~mL}^{-1}\right)$. The blood concentration of platelets was determined on an automated haematology 
analyser (Technicon $\mathrm{H}^{*} 2$, Bayer Diagnostics, SaintDenis, France).

Blood for CRP determination was collected in citrated tubes and centrifuged at $2,000 \times g$ for $20 \mathrm{~min}$ at $4{ }^{\circ} \mathrm{C}$. The protein concentration of CRP was determined with a sensitive ELISA method using antibodies (DAKO).

\section{Analysis}

Data are reported as the mean \pm SD. Data were analysed as the area under the curve (AUC) using the trapezoidal rule. Comparisons were performed with the Kruskal-Wallis test for comparison between multiple groups. The level of significance was set at $5 \%$. When p-values were significant, the individual groups were compared by the Mann-Whitney U-test. Data were also analysed for changes over time by Friedman repeated measures of analysis of variance on ranks.

\section{Results}

\section{Pulmonary function}

All subjects were able to perform the body plethysmographical manoeuvres, except one subject who could not be taught the panting required for measurement of sGaw. Inhaled heparin did not affect any of the lung function variables. Differences between the AUC did not reach statistical significance (FEV1 p=0.992; FVC p=0.982; PEF p=0.887; sGaw: $\mathrm{p}=0.807)$.

As expected, there was a slight physiological increase over time, but this only reached statistical significance for a few variables and doses (FEV1: 200,000 IU, $p=0.04$; FVC: 200,000 IU, $p=0.05$, 300,000 IU, $p=0.01$; PEF: 100,000 IU, $p=0.01$; sGaw: $100,000 \mathrm{IU}, \mathrm{p}<0.001,200,000 \mathrm{IU}, \mathrm{p}=0.03,300,000 \mathrm{IU}$, $\mathrm{p}=0.03)$.

\section{Systemic effects}

Activated partial thromboplastin time. Administration of inhaled heparin did not result in any significant changes in the AUC for APTT. When the data were analysed over time, there was a significant change after administration of 400,000 IU of inhaled heparin $(p=0.047)$, indicating that the highest dose of heparin increased APTT. The peak values were found 1 and $3 \mathrm{~h}$ after the start of the last nebulization (fig. 1).

Antifactor-Xa. Administration of inhaled heparin resulted in significant, dose-dependent changes in the AUC for anti-Xa activity ( $\mathrm{p}=0.005$ ) (fig. 2). Inhalation of $100,000 \mathrm{IU}$ heparin increased anti-Xa activity from $0.006 \pm 0.02$ to $0.014 \pm 0.03 \mathrm{IU} \cdot \mathrm{mL}^{-1}$. Inhalation of 200,000 IU heparin resulted in a small but insignificant increase from $0.016 \pm 0.04$ to $0.046 \pm 0.07 \mathrm{IU} \cdot \mathrm{mL}^{-1}$ $6 \mathrm{~h}$ after inhalation $(\mathrm{p}=0.1736)$. After inhalation of $300,000 \mathrm{IU}$, anti-Xa activity increased from $0.006 \pm$ 0.02 to $0.062 \pm 0.07 \mathrm{IU} \cdot \mathrm{mL}^{-1}$ after $3 \mathrm{~h} \quad(\mathrm{p}=0.1736)$.

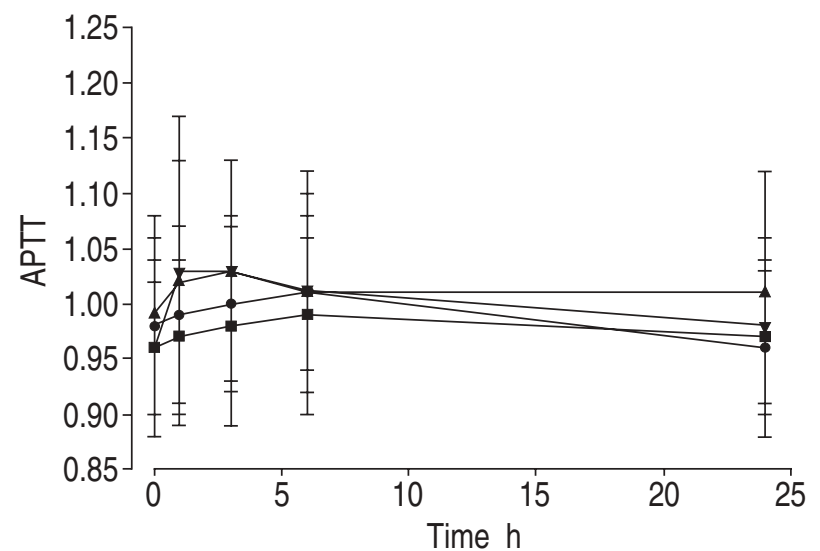

Fig. 1. - The effect of inhalation of heparin in increasing doses ( 100,000 International Units (IU); $\mathbf{\square}$ : 200,00 IU; $\boldsymbol{\Delta}$ : 300,000 IU; $\boldsymbol{\nabla}: 400,000 \mathrm{IU})$ is shown on the activated partial thromboplastin time (mean \pm SD). APTT: activated partial thromboplastin time.

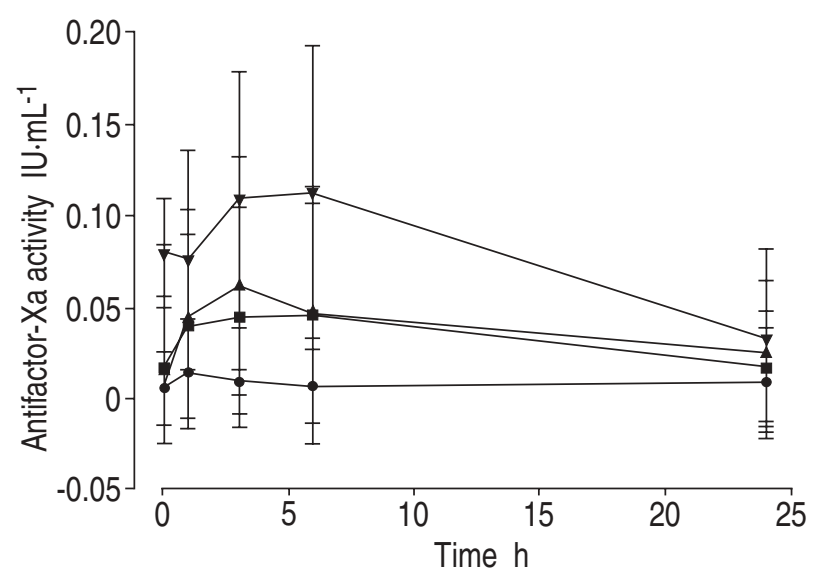

Fig. 2. - The effect of inhalation of heparin in increasing doses 100,000 International Units (IU); $\mathbf{a}$ : 200,00 IU; $\boldsymbol{\Delta}$ : 300,000 IU; $\nabla$ : 400,000 IU) is shown on the antifactor-Xa activity (mean $\pm \mathrm{SD})$.

Inhalation of $400,000 \mathrm{IU}$ heparin resulted in a significant increase in anti-Xa activity from $0.08 \pm$ 0.03 to $0.113 \pm 0.08 \mathrm{IU} \cdot \mathrm{mL}^{-1} 6 \mathrm{~h}$ after administration $(\mathrm{p}=0.009)$. Anti-Xa activity had decreased to $0.032 \mathrm{IU} \cdot \mathrm{mL}^{-1} 24 \mathrm{~h}$ later. Anti-Xa also changed significantly over time after inhalation of 200,000 $(\mathrm{p}=0.034), 300,000(\mathrm{p}=0.004)$, and 400,000 IU heparin $(\mathrm{p}=0.002)$.

Tissue factor pathway inhibitor. The AUC for TFPI did not change significantly $(\mathrm{p}=0.257)$, although the administration of 400,000 IU heparin resulted in an increase in TFPI from $48.0 \pm 13.6$ to $76.2 \pm 38.4 \mathrm{ng} \cdot \mathrm{mL}$ $1 \mathrm{~h}$ after inhalation (fig. 3). There was a significant release of TFPI with time for all doses of heparin $(100,000 \mathrm{IU}, \mathrm{p}=0.011 ; 200,000 \mathrm{IU}, \mathrm{p}=0.011$; 300,000 IU, $\mathrm{p}=0.006 ; 400,000$ IU, $\mathrm{p}<0.001$ ).

Whole blood clotting time, platelets, von Willebrand factor and C-reactive protein. Administration of inhaled heparin did not cause any change in the AUC for WBCT, platelets, vWF or CRP. When 


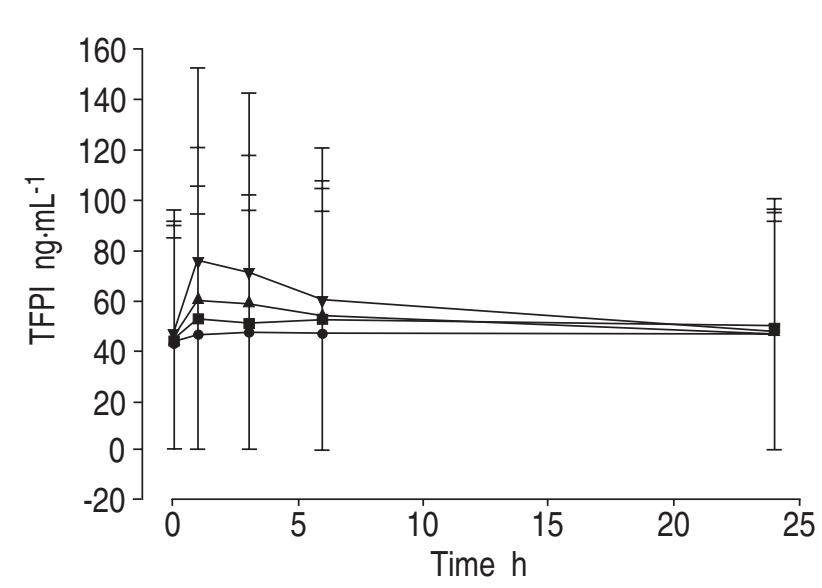

Fig. 3.-The release of tissue factor pathway inhibitor (TFPI) (mean \pm SD) after inhalation of increasing doses of heparin ( 100,000 International Units (IU); $\mathbf{\square}: 200,00$ IU; $\boldsymbol{\Delta}$ : 300,000 IU; ק: 400,000 IU).

analysed over time, there was a decrease in CRP after inhalation of 100,000 IU heparin, but no change after inhalation of any other dose. None of the other variables changed over time.

Adverse effects. None of the volunteers reported spontaneous, prolonged, or excessive bleeding, or breathing difficulties after heparin inhalation.

Two volunteers complained of a headache at the end of the inhalation day, a very warm day with temperatures $\leqslant 28^{\circ} \mathrm{C}$ in the body plethysmograph, after inhaling doses 2 and 3, respectively. One volunteer complained of headache immediately after inhalation of dose 3 . All symptoms disappeared when the volunteers went outside. One volunteer complained of a "dry spot" in the throat after inhalation of doses 2 and 3, but had no complaints after dose 4 . No other side-effects were reported.

\section{Discussion}

The present study is the first to determine the effect of a well-known quantified intrapulmonary dose of heparin on pulmonary function and systemic coagulation. It demonstrates that inhalation of $\leqslant 32,000 \mathrm{IU}$ of unfractionated heparin as an LRT dose is safe, with respect to pulmonary function and systemic coagulation. To deliver this dose by a Sidestream jet nebulizer driven at a flow rate of $10 \mathrm{~L} \cdot \mathrm{min}^{-1}$ requires a nebulizer charge of 400,000 IU heparin, as has been shown in a previous study [11].

Pulmonary function was recorded several times after heparin inhalation with all doses of heparin in the present study, but no effect on any of the pulmonary function variables was found. Thus, inhalation of heparin is safe with respect to pulmonary function in healthy volunteers. Similarly, a previous study demonstrated no immediate effects on pulmonary function of a single dose of inhaled heparin [12].

The present study demonstrates that inhaled heparin has an effect on the circulating blood, by increasing anti-Xa and APTT, and on the release of TFPI from the endothelial cells, whereas no adverse or anti-inflammatory effects were found (platelets, CRP). In a previous study, it was noted that following a single dose of inhaled ${ }^{99 \mathrm{~m}} \mathrm{Tc}$-labelled heparin, only small amounts of heparin could be found in the systemic circulation. The present study confirmed this finding by measuring the anti-Xa activity. The small increase in anti-Xa activity probably reflected the fact that most of the heparin that has reached the blood is associated with the endothelial cells. This has been demonstrated in animal studies following oral administration of heparin or instillation of heparin into the trachea [13, 14].

A previous study administering low molecular weight (LMW) heparin by inhalation observed a dose-dependent increase in anti-Xa activity, with a maximal value of $0.343 \pm 0.196 \mathrm{IU} \cdot \mathrm{mL}^{-1}$, while there was no effect on APTT [15]. In the present study there was an increase in anti-Xa, with a maximal value of $0.113 \mathrm{IU} \cdot \mathrm{mL}^{-1}$, together with an increase in APTT over time after administration of the highest dose of unfractionated heparin. However, absolute levels of anti-Xa cannot be compared due to the use of different chromogenic assays and calibrators in the two studies.

In another study, unfractionated heparin in doses of $700,1,300$, and $2,000 \mathrm{IU} \cdot \mathrm{kg}^{-1}$ (nebulizer charge) were administered by ultrasonic nebulization [12]. The response in anti-Xa was variable and independent of dose, but, on average, of a much larger magnitude than in the present study (a factor 7 versus a factor 1.5). This discrepancy is hard to explain as the particle-size distribution for an ultrasonic nebulizer is larger than for a jet nebulizer, causing an estimate of the largest LRT dose of their study to be comparable to the smallest LRT dose of 7,000 IU in the present study.

TFPI is bound to the proteoglycans lining the luminal surface of the endothelial cells and is known to be released by intravenous or subcutaneous heparin. The present study demonstrated that TFPI is also released from the endothelium by heparin administered by inhalation. TFPI is a feedback inhibitor of the extrinsic pathway of coagulation; heparin enhances the rate at which TFPI inhibits tissue factor/factor VIIa complex. This action probably contributes to the antithrombotic properties of heparin [16, 17]. The LMW inhalation study found a $35 \%$ increase in TFPI levels after inhalation of 54,000 IU of LMW heparin (jet nebulizer charge) [15]. The 55\% increase in TFPI in the study probably reflected a larger LRT dose with unfractionated heparin.

vWF was unaffected by heparin inhalation. It is mainly produced by endothelial cells and released from these as part of the primary haemostasis. Heparin binds to vWF thereby inhibiting irreversible platelet binding to subendothelial structures. This mechanism may contribute to the haemorrhagic sideeffects of heparin administration [18]. Like TFPI, $\mathrm{vWF}$ is released from endothelial cells, but the lack of response in vWF concentration demonstrates that the mechanisms for the release of the two factors must differ. 
The concentration of platelets was unaffected by increasing doses of heparin. Platelets were measured in order to document the absence of heparin-induced thrombocytopenia. CRP was largely unaffected by heparin inhalation. A significant decrease over time after inhalation of $100,000 \mathrm{IU}$ heparin must be explained by chance. CRP would not be expected to be affected in normal healthy volunteers without evidence of inflammatory diseases.

The large intersubject variation in response to TFPI and anti-Xa demonstrated that knowledge concerning the fate of inhaled heparin in the body is insufficient. As previously mentioned, heparin is stored in endothelial cells, but mast cells and macrophages also serve as reservoirs of heparin [19]. As heparin is also synthesized and metabolized, the pharmacodynamics are likely to be complex. These factors preclude this route of administration for effects other than local, as an anti-inflammatory agent in airway disease.

The present study has shown that a single dose of inhaled heparin is safe. Thus, studies of the long-term safety of inhaled heparin in normal subjects and in patients with obstrucitve airways disease may be planned, bearing in mind that the LRT deposition may be greater in the latter group of subjects.

To conclude, inhalation of $\leqslant 32,000$ International Units, as a lower respiratory tract dose, of unfractionated heparin did not affect pulmonary function. A dose-dependant anticoagulant effect could be demonstrated on the circulating blood (antifactor$\mathrm{Xa}$, activated partial thromboplastin time) and the endothelial cells as release of tissue factor pathway inhibitor. However, these changes were small and of no clinical relevance. The authors therefore consider inhalation of heparin in these or smaller doses to be safe with respect to pulmonary function and systemic anticoagulation.

Acknowledgements. The authors would like to thank Leo Pharmaceutical Ltd for the donation of heparin.

\section{References}

1. Garrigo J, Danta I, Ahmed T. Time course of the protective effect of inhaled heparin on exercise induced asthma. Am J Respir Crit Care Med 1996; 153: 1702-1707.

2. Diamant Z, Timmers MC, van der Veen H, Page C, van der Meer FJ, Sterk PJ. Effect of inhaled heparin on allergen induced early and late asthmatic responses in patients with atopic asthma. Am J Respir Crit Care Med 1996; 153: 1790-1795.
3. Kuna P, Antczak M. The effect of inhaled heparin on allergen induced bronchial hyperresponsiveness in asthmatic patients. Allergy 1995; 50: 25-26.

4. Kalpaklioglu AF, Demirel YS, Saryal S, Misirgil Z. Effect of pretreatment with heparin on pulmonary and cutaneous response. J Asthma 1997; 34: 337-343.

5. Ceyhan B, Celikel T. Effect of inhaled heparin on adenosine induced bronchial hyperreactivity. Int J Clin Pharm Therapeutics 1997; 35: 208-213.

6. Crimi N, Polossa R, Magri S, Armato F, Santonocito $\mathrm{G}$, Mistretta A. Attenuation of the airways responsiveness to AMP by inhaled heparin in asthmatic subjects. Am J Respir Crit Care Med 1995; 151: A130.

7. Pavord I, Mudassar T, Bennets J, Wilding P, Knox A. The effect of inhaled heparin on bronchial reactivity to sodium metabisulphite and methacholine in patients with asthma. Eur Respir J 1996; 9: 217-219.

8. Mattys H, Köhler D. Pulmonary deposition of aerosols by different mechanical devices. Respiration 1985; 48: 269-276.

9. Wood JA, Wilson RSE, Bray C. Changes in salbutamol concentration in the reservoir solution of a jet nebulizer. Br J Dis Chest 1986; 80: 164-169.

10. Bendstrup KE, Chambers C, Jensen JI, Newhouse MT. Characterization of heparin aerosols generated in jet and ultrasonic nebulizers. J Aerosol Med 1999; 12: $17-25$.

11. Bendstrup KE, Chambers CB, Jensen JI, Newhouse MT. Lung deposition and clearance of inhaled ${ }^{99 \mathrm{~m}} \mathrm{Tc}$ heparin in healthy volunteers. Am J Respir Crit Care Med 1999; 160: 1653-1658.

12. Hellgren M, Högnevik K, Blombäck M. Heparin aerosol effect on blood coagulation and pulmonary function. Thromb Res 1981; 21: 493-502.

13. Hiebert LM, Wice SM, Jaques LB. Antithrombotic activity of oral unfractionated heparin. $J$ Cardiovasc Pharmacol 1996; 28: 26-29.

14. Mahadoo J, Hiebert LM, Jaques LB. Vascular sequestration of heparin. Thromb Res 1977; 12: 79-90.

15. Harenberg J, Malsch R, Angelescu M, et al. Anticoagulant effects and tissue factor pathway inhibitor after intrapulmonary low molecular weight heparin. Blood Coagul Fibrinolysis 1996; 7: 477-483.

16. Novotny WF. Tissue factor pathway inhibitor. Semin Thromb Hemostasis 1994; 20: 101-108.

17. Abildgaard V, Sandset PM, Lindahl AK. Tissue factor pathway inhibitor. In: Poller ed. Blood coagulation. Churchill Livingstone, London, 1993; pp. 105124.

18. Sobel M, McNeill PM, Carlson PL, et al. Heparin inhibition of von Willebrand factor dependent platelet function in vitro and in vivo. J Clin Invest 1991; 87: 1787-1793.

19. Mahadoo J, Jaques LB. Cellular control of heparin in blood. Med Hypotheses 1979; 5: 835-841. 